\title{
Urban farmers markets as a strategy to increase access to and consumption of fresh vegetables among SNAP and non-SNAP participants: Results from an evaluation
}

\author{
Rebecca C. Woodruff a * and \\ Kimberly J. Arriola ${ }^{b}$ \\ Emory University
}

Kia Powell-Threets c

Georgia D epartment of Public Health

\author{
K. Rashid Nuri d and Carol Hunter e \\ Truly Living Well Center for Natural Urban \\ Agriculture
}

Michelle C. Kegler ${ }^{\mathrm{f}}$

Emory University

Submitted February 5, 2018/ Revised April 30 and May 22, 2018 / Accepted May 22, 2018 /

Published online July 6, 2018

Citation: Woodruff, R. C., Arriola, K. J., Powell-Threets, K., Nuri, K. R., Hunter, C., \& Kegler, M. C. (2018).

Urban farmers markets as a strategy to increase access to and consumption of fresh vegetables among SNAP and non-SNAP participants: Results from an evaluation. Journal of A griculture, F ood Systems, and Community D evelopment, 8(2), 93-105. https:/ / doi.org/ 10.5304/ jafscd.2018.082.013

Copyright (c) 2018 by the Authors. Published by the Lyson Center for Civic Agriculture and Food Systems. Open access under CC BY license.

\begin{abstract}
Inadequate access to healthy foods is an important determinant of dietary intake among low-income populations in the United States. This study reports

a * Corresponding author: Rebecca C. Woodruff, MPH, D octoral Candidate, D epartment of Behavioral Sciences and Health Education, Rollins School of Public Health, Emory University; 1518 Clifton Road NE; Atlanta, GA 30322 USA; +1-404-7277253; rwoodr2@emory.edu

b Kimberly J. Arriola, PhD , MPH, Professor, Emory Prevention Research Center, D epartment of Behavioral Sciences and Health Education, Rollins School of Public Health, Emory University; Atlanta, GA 30322 USA; kjacoba@emory.edu

c Kia Powell-Threets, MS, D eputy D irector, Georgia D epartment of Public Health, Chronic Disease Prevention Section, Reporting and Evaluation Unit; 2 Peachtree Street NW, Suite 16-203; Atlanta, GA 30303 USA; kia.powellthreets@dph.ga.gov

d K. Rashid Nuri, MSc, Founder and Chief Executive Officer, Truly Living Well Center for Natural Urban Agriculture; P.O. Box 90841; East Point, GA 30364 USA; rashid@trulylivingwell.com
\end{abstract}

the results of an evaluation of two urban farmers markets in metro Atlanta, which received funding to implement Electronic Benefits Transfer card readers to accept Supplemental Nutrition Assistance Program (SNAP) benefits as a form of payment. In Spring 2013, 179 farmers market

e Carol Hunter, BA, Chief Administrative Officer, Truly Living Well Center for Natural Urban Agriculture; P.O. Box 90841; East Point, GA 30364 USA; carol@ trulylivingwell.com

${ }^{f}$ Michelle C. Kegler, DrPH, MPH, Professor, Emory Prevention Research Center, D epartment of Behavioral Sciences and Health Education, Rollins School of Public Health, Emory University; Atlanta, GA 30322 USA; mkelger@emory.edu

\section{Funding Disclosure}

This evaluation was supported by a contract from the G eorgia D epartment of Public Health, Division of Health Promotion (\#40500-032-13120764), which was funded by a cooperative agreement with Centers for D isease Control and Prevention (CDC) as part of the Communities Putting Prevention to Work initiative (U58-D P002005-01S2). The findings and conclusions in this paper are those of the authors and do not necessarily represent the official position of the state of G eorgia or the CDC. 
customers completed self-administered paper surveys to assess the extent to which they received SNAP benefits, their patterns of using the market, and their self-reported changes in access to and consumption of fresh vegetables as a result of the markets. Results indicate that $28 \%$ of surveyed customers received SNAP benefits; however, only $20 \%$ of SNAP recipients reported that they were from the immediately surrounding community (1 mile away or less). Among returning customers, $74.2 \%$ strongly agreed that the markets made it easier to purchase fresh vegetables, and $64.5 \%$ reported eating more fresh vegetables as a result of the markets. Results suggest that market customers perceive that the farmers markets increase their access to and consumption of fresh vegetables, particularly among SNAP recipients. However, greater outreach is needed to members of the immediately surrounding community, many of whom receive SNAP and may benefit from increased access to the produce sold at the farmers markets.

\section{Keywords}

Farmers Markets; Environment; Diet; Nutrition; Fruit; Vegetable; Program Evaluation; Adults, Supplemental Nutrition Assistance Program; United States

\section{Introduction and Literature Review}

A growing body of research suggests that many neighborhoods in the United States lack equitable access to healthy foods (Caspi, Sorensen, Subramanian, \& Kawachi, 2012; Larson, Story, \& Nelson, 2009). For example, neighborhoods composed of low-income and predominately minority residents have limited access to full-service supermarkets (Moore \& D iez Roux, 2006; Zenk et al., 2005) and lower total availability of healthy foods compared to more affluent neighborhoods (Franco, Diez Roux, G lass, Caballero, \& Brancati, 2008; Morland \& Filomena, 2007). G reater access to healthy foods and healthy food retailers has been linked with better dietary outcomes (Bodor, Hutchinson, \& Rose, 2013; Bodor, Rose, Farley, Swalm, \& Scott, 2008; Franco et al., 2009) and lower body mass index (Morland, Diez Roux, \& Wing, 2006). This suggests that access to healthy foods may be an important characteristic of healthpromoting neighborhood environments.

In response to the growing recognition of the role local food environments may play in influencing dietary behaviors, increasing access to healthy food options has become a national public health priority. Federal health promotion programs, such as the Communities Putting Prevention to Work (CPPW) program, have focused on modifying local food environments to make them more supportive of healthy eating (Bunnell et al., 2012). This strategy aligns with one of the national objectives of Healthy People 2020--to increase the proportion of Americans who have access to a food retail outlet that sells a variety of foods that are encouraged by the D ietary $\mathrm{G}$ uidelines for Americans (D epartment of Health and Human Services, n.d.). This strategy is also consistent with theoretical frameworks of health behavior, such as Cohen's Structural Model of Health Behavior, which suggest that the availability of health-promoting resources is an important determinant of engaging in health-promoting behaviors (Cohen, Scribner, \& Farley, 2000).

Access to healthy foods is a multidimensional concept that encompasses availability, accessibility, affordability, accommodation, and acceptability of healthier food options (Caspi et al., 2012). Strategies to improve access to healthy foods have included opening new retailers of healthy foods within a community, encouraging existing retailers to stock healthier options, and making healthy food options more affordable to low-income consumers (Story, Kaphingst, Robinson-O 'Brien, $\&$ G lanz, 2008). O ne method of increasing the affordability of fresh fruits and vegetables is to equip farmers markets with Electronic Benefits Transfer (EBT) card readers so that low-income Americans who participate in the Supplemental Nutrition Assistance Program (SNAP, formerly known as the food stamp program) may use their benefits to purchase fresh produce.

However, the extent to which these initiatives will improve dietary behaviors among SNAP participants remains an area of active research. To date, most research regarding introducing EBT card readers at farmers markets has focused on describing the factors influencing the adoption of 
this technology (Hasin \& Smith, 2018; Roubal, Morales, Timberlake, \& Martinez-D onate, 2016; Ward, Slawson, Wu, \& Jilcott Pitts, 2015) or on the effect of these initiatives on SNAP redemption rates and market sales (Buttenheim, Havassy, Fang, Glyn, \& Karpyn, 2012; Hasin, Smith, \& Stieren, 2016; Jones \& Bhatia, 2011). Few studies have focused on nutrition and dietary behavior or perceived access to healthy foods as outcomes (K rokowski, 2016). Research regarding the ability of these initiatives to improve fruit and vegetable intake is needed to evaluate the potential significance of these programs for improving population-level dietary change.

Through the CPPW program, the Centers for Disease Control and Prevention (CD C) funded 50 communities to implement local environmental changes focused on obesity prevention and tobacco control (Bunnell et al., 2012). The G eorgia Department of Public Health (DPH) used CPPW funding to expand access to fresh fruits and vegetables among local residents by purchasing EBT card readers for two local farmers markets operated by Truly Living Well Center for Natural Urban Agriculture (TLW) in Atlanta, GA. This article presents results from an evaluation of TLW's farmers markets, following the implementation of EBT card readers. The evaluation sought to answer the following questions: (1) What is the current reach of the TLW market, as measured by the demographic and socioeconomic characteristics of existing customers? (2) What are the patterns of TLW farmers market use among customers? (3) What perceived changes in access to and consumption of fresh vegetables do returning customers report as a result of the market? and (4) How do these characteristics vary between SNAP participants and non-participants?

\section{Applied Research Methods}

Research $D$ esign and $V$ ariables

This evaluation used a one-group post-test only design to evaluate the Truly Living Well Center for Natural Urban Agriculture's O pen Air Farmers Markets (Shadish, Cook, \& Campbell, 2002). Demographic and socioeconomic characteristics of the market shoppers, their patterns of using the market, and their perceptions about how the market impacted their access to and consumption of fresh vegetables were used as dependent variables. Receipt of SNAP benefits served as the independent variable.

D escription of the Truly L iving W ell C enter for $\mathrm{N}$ atural U rban A griculture's 0 pen A ir Farmers Mark ets and Setting

TLW is a 501(c)(3) nonprofit organization that has been operating in metro Atlanta since 2006. TLW's mission is to grow better communities by connecting people with the land through education, training, and demonstration of economic success in natural urban agriculture (Truly Living Well Center for Natural Urban Agriculture, n.d.). TLW's flagship initiative involves operating urban farms in metro Atlanta using Certified Naturally G rown methods (Certified Naturally G rown, n.d.). Each year, these farms produce an estimated 30,000 pounds $(13,600 \mathrm{~kg})$ of fresh fruit, vegetables, herbs, and flowers, which are sold to the general public at open-air farmers markets located on site at the urban farms. These markets exclusively sell produce grown by TLW; no other vendors sell products at these markets. In addition to these activities, TLW also runs a community-supported agriculture program (CSA) and offers a variety of educational and outreach activities for both adults and children, including urban farm tours, volunteer opportunities, summer camps, and urban agriculture training. In 2012, D PH used CPPW funding to enable TLW to purchase EBT card readers so that the farmers markets could accept SNAP as a form of payment.

At the time of this evaluation, TLW operated two urban farmers markets, which were located in the Sweet Auburn/ Old Fourth Ward neighborhoods as well as the city of East Point in metro Atlanta, G eorgia. Both farmers markets were open for business year-round during afternoon and evening hours. The Sweet Auburn/ Old Fourth Ward location was open on Fridays, and the East Point location was open on Wednesdays. Figure 1 displays the locations of the two TLW farmers markets to provide context for this evaluation.

The census tracts in which TLW markets were located were composed of primarily Black residents (55.1-77.1\% per census tract) with a greater share 
of neighborhood

households accessing SNAP (15.323.8\%) compared to the overall metro Atlanta population $(12.4 \%)$ (U.S. Census Bureau, n.d.). Although several other farmers markets were located in the vicinity of the Sweet Auburn/ Old Fourth Ward neighborhoods, many of them did not accept EBT as a form of payment at the time of this evaluation (U.S. Department of Agriculture [USD A], 2013). No other known farmers markets existed in the city of East Point at the time of this evaluation (USDA, 2013).

\section{Sample}

This evaluation sought to generate information about the customer base of the TLW farmers markets. A convenience sample of participants who shopped at the markets on nine days in Spring 2013 were invited to participate in the study. Eligible participants were adults aged 18 or older who were shopping at the TLW farmers markets and who had not completed the survey previously. The recruitment goal was to enroll as many shoppers at the TLW markets in the study as
Figure 1. The Proportion of Households Receiving Supplemental Nutrition Assistance Program (SNAP) Benefits per Census Tract in Neighborhoods Surrounding Truly Living Well Center for Natural Urban Agriculture Farm Market Locations, Atlanta, Georgia, USA; 2013

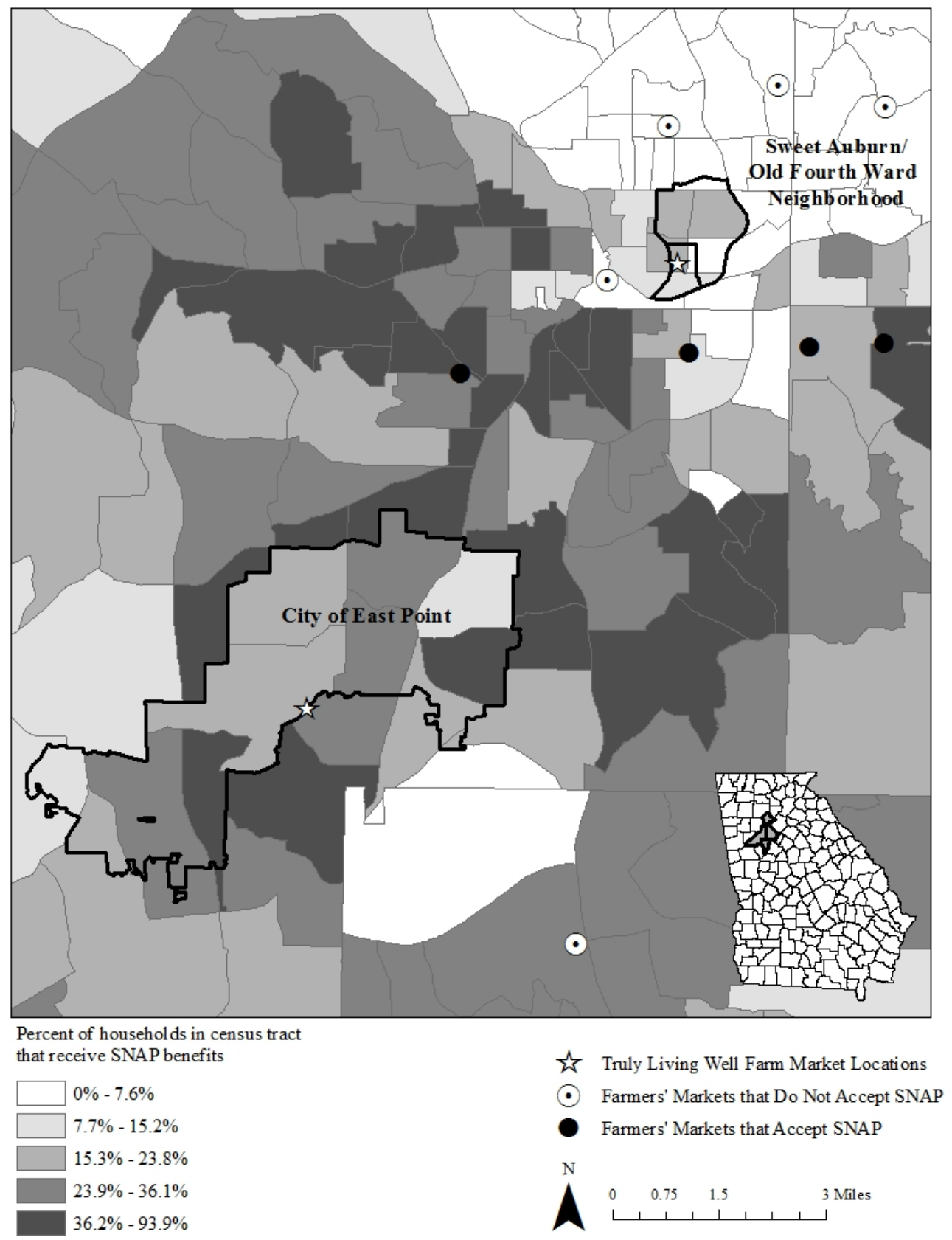

possible during the nine recruitment days. Response rates were not systematically tracked.

Instrumentation

The instrument used for this study was a selfadministered, English-language, pen-and-paper 
survey that contained 34 items and took approximately 10 to 15 minutes to complete. The survey included questions about demographic characteristics, attendance at the market, perceived changes in access to and consumption of fresh vegetables, perceived benefits of organic and locally grown produce, and receipt of SNAP benefits.

D emographic C haracteristics: Standard demographic questions were used to measure age, gender, race, employment status, education, income, and history of volunteering with or being employed by TLW. Respondents were also asked to respond yes or no to the question, "Have you ever run out of food in the last 12 months because you could not afford to buy more?" as a potential indicator of food insecurity. D emographic characteristics were treated as dependent variables in all statistical tests assessing differences between SNAP and non-SNAP participants.

Patterns of Market U se: Frequency of market use was measured by asking participants how often they visit the farmers market on a monthly basis; this measure was adapted from a publicly available survey from an evaluation of a similar initiative (Reed, G rost, Mantinan, \& G oldenhar, 2013). Participants could either indicate that this was their first time attending the market or record the number of times per month that they attended the market (less than once- 4 times per month). The survey also included a question asking participants to indicate what year they began attending the market. Responses included that this was their first season attending the market, or the years 20062012. The survey also included a question about how far respondents traveled to get to the farmers market (less than 1 mile, 1-5 miles, 6-10 miles, 1120 miles, or more than 20 miles). A single, checkall question was used to assess methods of transportation to the market (e.g., car, bike, train, bus, on foot, or some other method). Patterns of market use were treated as dependent variables in all statistical tests assessing differences between SNAP and non-SNAP participants.

Percived change in access to and consumption of fresh vegetables: Perceived change in access to fresh vegetables was assessed using two questions asking participants to what extent they agreed or disagreed that the TLW farmers market made it easier to purchase fresh vegetables in their community and helped to offer a large selection of fresh vegetables in their community. Participants could select their responses using a 4-point Likert scale ranging from strongly disagree to strongly agree. These survey questions were developed for this study.

Self-reported change in vegetable consumption was measured using a single item asking participants to report to what extent they had been eating more fresh vegetables as a result of shopping at the TLW farmers market, relative to before they started shopping there. Response options were: this was their first time attending the market; no, fewer vegetables; no, the same amount of vegetables; yes, a little more vegetables; or yes, a lot more vegetables. This question was adapted from a previous evaluation of a similar initiative (Reed et al., 2013). Perceived changes in access to and consumption of fresh vegetables were treated as dependent variables in all statistical tests assessing differences between SNAP and non-SNAP participants.

Receipt of SN A P Benefits: The independent variable was assessed by asking participants to respond yes or no to the question, "In the past 12 months, did anyone in your household receive food stamps or a food stamp benefit card?"

\section{Procedures}

In 2013, D PH awarded a contract to the Emory Prevention Research Center (EPRC) to evaluate the TLW farmers markets; the EPRC, which managed the evaluation contract, was not involved in the design or implementation of this or other TLW initiatives. Representatives from DPH, TLW, and the EPRC jointly determined the evaluation questions and methodology. O nce the survey instrument was finalized, trained graduate research assistants from the EPRC distributed self-administered intercept surveys to a convenience sample of customers on site at the two TLW farmers markets on nine days in April and May 2013. Because the primary purpose of this project was quality improvement, the Emory University Institutional 
Review Board determined that this project was non-research program evaluation and did not require IRB approval.

D ata A nalysis

D ata were analyzed in SAS 9.3 (2012, SA S Institute, Inc., Cary, NC, USA) using descriptive statistics, including frequencies, proportions, and means. Analyses focused on describing the demographic characteristics of evaluation participants and their patterns of market use were conducted among the entire sample. Analyses focused on perceived change in perceived access to and consumption of fresh vegetables were restricted to customers who reported that they had attended the market at least once before $(n=93)$. Additionally, bivariate statistical tests--including chi-square tests, Fisher's exact tests, Wilcoxon-Mann-Whitney tests, and independent samples t-tests--were used as appropriate to assess differences between SNAP recipients and non-SNAP recipients on their demographic and socioeconomic characteristics, their patterns of TLW market use, and perceived impact of the market on their access to and consumption of fresh vegetables.

\section{Results}

In total, 184 customers completed the survey (52\% from the Sweet Auburn/ Old Fourth Ward market and $48 \%$ from the East Point market). Five surveys were later excluded, either because the participant was found to have taken the survey before $(n=1)$ or because of missing data on key variables $(n=4)$. This resulted in a final analytic sample size of 179 participants.

D emographic and Socioeconomic C haracteristics of TL W Farmers M ark et C ustomers

Over one-quarter (27.9\%) of the sample reported that they receive SNAP benefits (Table 1). The majority of respondents were Black or African American (81.4\%), middle-aged (mean age: 45.5 years, $\mathrm{SD}=15.4)$, women $(68.5 \%)$, who were employed either full- (47.5\%) or part-time (16.8\%). The racial composition of the evaluation sample was similar to residents of the census tracts where each farmers market was located (e.g., 55.0\% Black residents in the Sweet Auburn/ Old Fourth Ward census tract vs. 53.8\% from the sample at that site; 77.1\% Black residents from the East Point census tract vs. $76.7 \%$ at that site; data not shown). Most reported that they had a college degree (36.3\%) or higher (26.8\%). Relatively few respondents (12.5\%) reported an annual household income of US $\$ 10,000$ or less, whereas $40.9 \%$ reported an annual household income more than US\$50,000. Interestingly, of customers who reported annual household incomes of US $\$ 10,000$ or less, $41 \%$ reported that they did not receive SNAP benefits. Approximately one in five shoppers in the sample (21.3\%) reported that they had run out of food at some time in the previous year because they could not afford to buy more. Approximately $19.0 \%$ of respondents reported a history of volunteering for, being employed by, or serving on the board of TLW in the previous 6 months.

SNAP recipients were more likely to report their race as Black or African American (75.0\%) relative to non-SNAP recipients $(60.5 \% ; \mathrm{p}<.05)$. SNAP recipients were also less likely to report fulltime employment $(\mathrm{p}=.001)$, reported lower educational attainment $(\mathrm{p}<.001)$ and income levels $(\mathrm{p}<.0001)$, and were more likely to report that they had run out of food in the previous year because they could not afford to buy more $(50.0 \%)$ relative to non-SNAP recipients $(10.2 \%$; $p<.0001)$. SNAP recipients were marginally more likely to report a volunteer or employment history with TLW (28.9\%) compared to non-SNAP recipients (15.5\%, $\mathrm{p}=0.05)$.

\section{Patterns of $\mathrm{M}$ ark et $\mathrm{U}$ se}

Just under half of the sample reported that they were attending the farmers markets for the first time (48.0\%; Table 2) and just over half of the sample reported that they were returning customers (52.0\%). Over one-quarter of the sample reported attending the market 3 to 4 times per month $(26.8 \%)$, though relatively few reported that they had been attending the market for 2 to 3 years $(10.6 \%)$ or 4 years or more $(10.6 \%)$. Many respondents reported that they traveled between 1 and 5 miles to get to the farmers market ( $45.8 \%$ ), and car was the most frequently reported form of transportation (87.2\%). Relatively few respondents came from less than a mile away (16.4\%) or 
Journal of Agriculture, Food Systems, and Community Development

ISSN: 2152-0801 online

https:/ / www.foodsystemsjournal.org

Table 1. Demographic and Socioeconomic Characteristics of Customers Recruited from Truly Living Well Center for Natural Urban Agriculture's Open Air Farm Markets by Receipt of Supplemental Nutrition Assistance Program (SNAP) Benefits

\begin{tabular}{|c|c|c|c|c|c|c|c|}
\hline \multirow{2}{*}{ TLW Site - n (\%) } & \multicolumn{2}{|c|}{$\begin{array}{l}\text { All Customers } \\
(\mathrm{N}=179)\end{array}$} & \multicolumn{2}{|c|}{$\begin{array}{l}\text { Receive SNAP } \\
\text { Benefits }(n=50)\end{array}$} & \multicolumn{2}{|c|}{$\begin{array}{l}\text { Do Not Receive } \\
\text { SNAP Benefits } \\
(n=129)\end{array}$} & \multirow[t]{2}{*}{ P-value } \\
\hline & & & & & & & \\
\hline Sweet Auburn/ Old Fourth Ward & 93 & $(52.0)$ & 26 & $(52.0)$ & 67 & $(51.9)$ & 0.99 \\
\hline East Point & 86 & $(48.0)$ & 24 & $(48.0)$ & 62 & $(48.1)$ & \\
\hline Age a - mean (SD) & 45.5 & $(15.4)$ & 43.81 & $(15.9)$ & 46.1 & $(15.2)$ & 0.39 \\
\hline \multicolumn{8}{|l|}{ Gender - n (\%) } \\
\hline Female & 122 & $(68.5)$ & 35 & $(71.4)$ & 87 & $(67.4)$ & 0.61 \\
\hline Male & 56 & $(31.5)$ & 14 & $(28.8)$ & 42 & $(32.6)$ & \\
\hline Missing & 1 & & 1 & & 0 & & \\
\hline \multicolumn{8}{|l|}{ Race -n (\%) } \\
\hline Black/ African American & 114 & $(81.4)$ & 36 & $(75.0)$ & 78 & $(60.5)$ & 0.04 \\
\hline White/ Caucasian & 49 & $(27.7)$ & 8 & (16.7) & 41 & (31.8) & \\
\hline Hispanic/ Latino & 3 & $(1.7)$ & 1 & $(2.1)$ & 2 & $(1.6)$ & \\
\hline Other & 11 & $(6.2)$ & 3 & $(6.3)$ & 8 & $(6.2)$ & \\
\hline Missing & 2 & & 2 & & 0 & & \\
\hline \multicolumn{8}{|l|}{ Employment Status - n (\%) } \\
\hline Working full time & 85 & $(47.5)$ & 15 & $(30.0)$ & 70 & $(54.3)$ & 0.001 \\
\hline Working part time & 30 & $(16.8)$ & 10 & $(20.0)$ & 20 & $(15.5)$ & \\
\hline Retired & 30 & $(16.8)$ & 7 & $(14.0)$ & 23 & $(17.8)$ & \\
\hline Not employed, homemaker, student, or on disabilit & 34 & $(19.0)$ & 18 & $(36.0)$ & 16 & $(12.4)$ & \\
\hline \multicolumn{8}{|l|}{ Highest Level of Education - $\mathrm{n}(\%)$} \\
\hline High School/GED or less & 19 & $(10.6)$ & 9 & $(18.0)$ & 10 & $(7.8)$ & \\
\hline Some college/ technical school & 47 & $(26.3)$ & 20 & $(40.0)$ & 27 & $(20.9)$ & 0.0003 \\
\hline College graduate & 65 & $(36.3)$ & 14 & $(28.0)$ & 51 & $(39.5)$ & \\
\hline Post-graduate or professional degree & 48 & $(26.8)$ & 7 & $(14.0)$ & 41 & $(31.8)$ & \\
\hline \multicolumn{8}{|l|}{ Income (US\$) - n (\%) } \\
\hline$\$ 10,000$ or less & 22 & $(12.5)$ & 13 & $(26.0)$ & 9 & $(7.1)$ & $<.0001$ \\
\hline$\$ 10,001-\$ 25,000$ & 34 & $(19.3)$ & 19 & $(38.0)$ & 15 & $(11.9)$ & \\
\hline$\$ 25,001-\$ 50,000$ & 35 & $(19.9)$ & 7 & $(14.0)$ & 28 & $(22.2)$ & \\
\hline$\$ 50,001$ or more & 72 & $(40.9)$ & 4 & $(8.0)$ & 68 & $(54.0)$ & \\
\hline Don't know/ Not sure & 13 & $(7.4)$ & 7 & $(14.0)$ & 6 & $(4.8)$ & \\
\hline Missing & 3 & & 0 & & 3 & & \\
\hline \multicolumn{8}{|l|}{$\begin{array}{l}\text { Have you ever run out of food in the last } 12 \text { months } \\
\text { because you could not afford to buy more? }\end{array}$} \\
\hline Yes & 38 & $(21.3)$ & 25 & $(50.0)$ & 13 & $(10.2)$ & $<0001$ \\
\hline No & 140 & $(78.7)$ & 25 & $(50.0)$ & 115 & $(89.8)$ & \\
\hline Missing & 1 & & 0 & & 1 & & \\
\hline $\begin{array}{l}\text { Ever volunteered for, been employed by, or served } \\
\text { on the board of TLW in the previous } 6 \text { months? }\end{array}$ & 34 & $(19.0)$ & 14 & $(28.9)$ & 20 & $(15.5)$ & 0.05 \\
\hline
\end{tabular}

Note. Chi square tests were used to assess differences in TLW site, gender, race (African American vs. white), employment status, education (college degree or higher vs. not), income, running out of food in the previous 12 months because you could not afford more, and volunteer status comparing customers who receive SNAP benefits to those who do not. Independent samples t-test was used to assess differences in age comparing customers who receive SNAP benefits to those who do not.

a Data are missing for three participants. 
traveled by foot, bicycle, or public transit (8.4\%).

SNAP recipients were similar to non-SNAP recipients regarding their frequency of attending the market and distance traveled to get to the market. However, SNAP recipients tended to have started attending the farmers markets more recently than non-SNAP recipients $(p<.05)$. SNAP recipients were also less likely to report having taken a car to get to the market (76.0\%) as compared to non-SNAP recipients $(91.5 \%$; $p<.05)$.

Perceived Changes in $\mathrm{A}$ coess to and $\mathrm{C}$ onsumption of Fresh V egetables

Returning customers who responded to the survey reported high levels of agreement that the TLW farmers market made it easy to purchase fresh vegetables in their community $(74.2 \%$ strongly agree, $17.2 \%$ agree) and helped offer a large selection of fresh vegetables in their community (64.5\% strongly agree, $25.8 \%$ agree; Table 3). There were no statistically significant differences in either of these responses between SNAP and nonSNAP recipients.

Results regarding the perceived changes in fresh vegetable consumption as a result of shopping at the farmers market were mixed. Approximately one-third of returning customers reported that they were eating the same amount of fresh vegetables as a result of shopping at the farmers market (34.4\%), that they were eating a little more fresh vegetables (30.1\%), or that they were eating a lot more fresh vegetables (34.4\%;

Table 2. Patterns of Use by Customers Recruited from Truly Living Well Center for Natural Urban Agriculture's Open Air Farm Markets by Receipt of Supplemental Nutrition Assistance Program (SNAP) Benefits

\begin{tabular}{|c|c|c|c|c|c|c|c|}
\hline & \multicolumn{2}{|c|}{$\begin{array}{l}\text { All Customers } \\
\qquad(\mathrm{N}=179)\end{array}$} & \multicolumn{2}{|c|}{$\begin{array}{l}\text { Receive SNAP } \\
\text { Benefits } \\
(n=50)\end{array}$} & \multicolumn{2}{|c|}{$\begin{array}{c}\text { Do Not Receive SNAP } \\
\text { Benefits } \\
(n=129)\end{array}$} & \multirow[b]{2}{*}{ P-value } \\
\hline & $\mathrm{n}$ & $(\%)$ & $\mathrm{n}$ & $(\%)$ & $\mathrm{n}$ & $(\%)$ & \\
\hline \multicolumn{8}{|l|}{ Frequency of Attendance } \\
\hline First time & 86 & $(48.0)$ & 25 & $(50.0)$ & 61 & $(47.3)$ & \multirow{4}{*}{0.95} \\
\hline Less than 1 time per month & 12 & $(6.7)$ & 3 & $(6.0)$ & 9 & $(7.0)$ & \\
\hline 1- 2 times per month & 33 & $(18.4)$ & 8 & $(16.0)$ & 25 & $(19.4)$ & \\
\hline 3- 4 times per month & 48 & $(26.8)$ & 14 & $(28.0)$ & 34 & $(29.4)$ & \\
\hline \multicolumn{8}{|l|}{ Length of Attendance } \\
\hline First time & 86 & $(48.0)$ & 25 & $(50.0)$ & 61 & $(47.3)$ & \multirow{5}{*}{0.04} \\
\hline First season & 25 & $(14.0)$ & 8 & $(16.0)$ & 17 & $(13.2)$ & \\
\hline 1 year ago & 30 & $(16.8)$ & 13 & $(26.0)$ & 17 & $(13.2)$ & \\
\hline $2-3$ years ago & 19 & $(10.6)$ & 3 & $(6.0)$ & 16 & $(12.4)$ & \\
\hline 4 years ago or more & 19 & $(10.6)$ & 1 & $(2.0)$ & 18 & $(14.0)$ & \\
\hline \multicolumn{8}{|l|}{ Travel Distance to TLW } \\
\hline Less than 1 mile & 29 & $(16.4)$ & 10 & $(20.0)$ & 19 & $(15.0)$ & \multirow{6}{*}{0.54} \\
\hline $1-5$ miles & 81 & $(45.8)$ & 18 & $(36.0)$ & 63 & $(49.6)$ & \\
\hline $6-10$ miles & 44 & $(24.9)$ & 15 & $(30.0)$ & 29 & $(22.8)$ & \\
\hline 11- 20 miles & 17 & $(9.6)$ & 5 & $(10.0)$ & 12 & $(9.4)$ & \\
\hline More than 20 miles & 6 & $(3.4)$ & 2 & $(4.0)$ & 4 & (3.1) & \\
\hline Missing & 2 & & 0 & & 2 & & \\
\hline \multicolumn{8}{|l|}{ Method of Transportation to TLW } \\
\hline Car & 156 & $(87.2)$ & 38 & $(76.0)$ & 118 & $(91.5)$ & \multirow[t]{2}{*}{0.03} \\
\hline Other method (foot, bike, train, or bus) & 15 & $(8.4)$ & 8 & $(16.0)$ & 7 & $(5.4)$ & \\
\hline
\end{tabular}

Note. Chi Square tests were used to assess differences in frequency of attendance and length of attendance, and Fisher's exact test was used to assess differences in travel distances to TLW and method of transportation between customers who receive SNAP benefits and those who do not. 
Table 3). Among SNAP recipients, 44\% reported eating a lot more fresh vegetables and 36\% reported eating a little more fresh vegetables compared to non-SNAP recipients, of whom 31\% reported eating a lot more and $28 \%$ reported eating a little more fresh vegetables $(p=0.08)$.

\section{Discussion}

This article describes results from an evaluation of two farmers markets in Atlanta, G eorgia, that received funding through the CPPW program to purchase additional EBT card readers so that they could accept SNAP benefits as a form of payment, thereby making their produce more affordable to low-income customers. In recent years, there has been growing interest in increasing low income people's access to farmers markets as a strategy to prevent chronic disease (Blanck, Thompson, Nebeling, \& Yaroch, 2011; Bunnell et al., 2012; Jones \& Bhatia, 2011); however, little evidence exists regarding the potential impact of these programs on perceived access to healthy foods and dietary behaviors (McCormack, Laska, Larson, \& Story, 2010). This study adds to the growing body of literature regarding the ability of urban farmers markets to reach low-income shoppers and the role that they may play in improving perceived access to healthy foods and dietary behaviors.

Results from this evaluation suggest that the TLW farmers markets succeeded at reaching customers from a range of socioeconomic backgrounds, including those who receive SNAP benefits, despite the fact that a large proportion of the sample reported educational, employment, and income levels indicative of higher socioeconomic status. Although the high proportion of SNAP recipients shopping at the farmers markets cannot be directly attributed to the introduction of EBT card readers, our survey found that SNAP recipients were more likely to have reported that they started attending the market recently compared to non-SNAP participants. These findings

Table 3. Perceived Changes in Access to Healthy Foods and Fresh Vegetable Consumption among Returning Customers Recruited from Truly Living Well Center for Natural Urban Agriculture's Open Air Farm Market by Receipt of Supplemental Nutrition Assistance Program (SNAP) Benefits

\begin{tabular}{|c|c|c|c|c|c|c|c|}
\hline & \multicolumn{2}{|c|}{$\begin{array}{l}\text { All Returning } \\
\text { Customers } \\
(\mathrm{N}=93)\end{array}$} & \multicolumn{2}{|c|}{$\begin{array}{l}\text { Returning Customers } \\
\text { Who Receive } \\
\text { SNAP Benefits } \\
(\mathrm{n}=25)\end{array}$} & \multicolumn{2}{|c|}{$\begin{array}{l}\text { Returning Customers } \\
\text { Who Do Not Receive } \\
\text { SNAP Benefits } \\
(n=68)\end{array}$} & \multirow[b]{2}{*}{ P-value } \\
\hline & $\mathrm{n}$ & (\%) & $\mathrm{n}$ & (\%) & $\mathrm{n}$ & (\%) & \\
\hline \multicolumn{8}{|c|}{ This Farm Market has made it easy to purchase fresh vegetables in my community } \\
\hline Strongly agree & 69 & $(74.2)$ & 19 & (76.0) & 50 & (73.5) & \multirow{4}{*}{0.80} \\
\hline Somewhat agree & 16 & $(17.2)$ & 4 & $(16.0)$ & 12 & $(17.7)$ & \\
\hline Somewhat disagree & 2 & $(2.2)$ & 1 & $(4.0)$ & 1 & $(1.5)$ & \\
\hline Strongly disagree & 6 & $(6.5)$ & 1 & $(4.0)$ & 5 & $(7.4)$ & \\
\hline \multicolumn{8}{|c|}{ This Farm Market has helped to offer a large selection of fresh vegetables in my community } \\
\hline Strongly agree & 60 & $(64.5)$ & 17 & $(68.0)$ & 43 & $(63.2)$ & \multirow{4}{*}{0.65} \\
\hline Somewhat agree & 24 & $(25.8)$ & 6 & $(24.0)$ & 18 & $(26.5)$ & \\
\hline Somewhat disagree & 3 & $(3.2)$ & 1 & $(4.0)$ & 2 & $(2.9)$ & \\
\hline Strongly disagree & 6 & $(6.5)$ & 1 & $(4.0)$ & 5 & $(7.4)$ & \\
\hline \multicolumn{8}{|c|}{$\begin{array}{l}\text { As a result of shopping at the TLW Farm Market, have you been eating more fresh vegetables than before you } \\
\text { started shopping here? }\end{array}$} \\
\hline Yes, a lot more & 32 & $(34.4)$ & 11 & $(44.0)$ & 21 & $(30.9)$ & \multirow{3}{*}{0.08} \\
\hline Yes, a little more & 28 & $(30.1)$ & 9 & $(36.0)$ & 19 & $(27.9)$ & \\
\hline No, the same amount & 32 & $(34.4)$ & 5 & $(20.0)$ & 27 & $(39.7)$ & \\
\hline No, fewer & 1 & $(1.1)$ & 0 & $(0.0)$ & 1 & $(1.5)$ & \\
\hline
\end{tabular}

Note. Wilcoxon-Mann-Whitney tests were used to assess differences between returning customers who do and do not receive SNAP benefits. 
suggest a potential association between the introduction of EBT card readers and increased use of the farmers market by SNAP participants. Interestingly, the market also served low-income customers who were not enrolled in SNAP benefits. This suggests that the farmers market may be a potential outreach site for enrolling low-income customers in public assistance programs, such as SNAP.

D espite the fact that a relatively large proportion of survey respondents reported receiving SNAP benefits, evaluation results indicated that the markets may not be reaching people from the immediately surrounding communities, which include areas with a high proportion of households on SNAP (U.S. Census Bureau, n.d.). Based on these results, greater outreach into neighborhoods immediately surrounding the markets is needed. At the time of this evaluation, TLW was planning to increase outreach efforts, in part, by enrolling in Georgia Fresh For Less, an incentive program that enables SNAP recipients to double their food purchases when they shop at participating markets (Wholesome Wave G eorgia, n.d.). Similar initiatives have been shown to result in improvements in fruit and vegetable consumption among SNAP recipients (Zimmerman, Roskos, Feller, \& D urward, 2016).

However, initiatives to increase the affordability of products sold at the market may be insufficient methods of attracting SNAP recipients. Results from a recent systematic review suggest that low-income consumers face numerous barriers to shopping at farmers markets. Although the introduction of EBT card readers at the TLW farmers markets addresses one of the most commonly cited barriers identified by this review (i.e., the perception that SNAP benefits are not accepted at farmers markets), low-income consumers perceive many other barriers not directly related to affordability (e.g., lack of racial and/ or ethnic diversity at the markets, mismatches between the farmers markets and personal lifestyles, etc.) (Freedman et al., 2016). It is possible that interventions solely focused on increasing the affordability of fresh produce may be insufficient for reaching low-income consumers; future programming should also address other components of access conceptualized by Caspi et al., including the availability, accessibility, accommodation, and acceptability of markets and their products (Caspi et al., 2012). More research is needed regarding how farmers markets can address these other dimensions of access to attract SNAP recipients as customers. Future studies should focus on documenting how SNAP customers learned about the farmers market, as well as what motivated and made it easier for them to shop at the market. These results could help inform future outreach efforts.

An important finding from this evaluation was that returning TLW farmers market customers reported improvements in both their perceived access to and consumption of fresh vegetables as a result of the markets. These results are consistent with other evaluations of farmers markets and similar initiatives in how they affect customers' dietary behavior. For example, an evaluation of two farmers markets in Los Angeles reported that 97$98 \%$ of customers agreed or strongly agreed that they eat more fruits and fresh vegetables because of the market (Ruelas, Iverson, Kiekel, \& Peters, 2012). Additionally, an evaluation of a fruit and vegetable stand in Cobb County, Georgia, found that $65 \%$ of participants reported eating more vegetables, and $55 \%$ reported eating more fruit since they began shopping at the produce stand (Woodruff et al., 2016). These results suggest that farmers markets may have a positive impact on the dietary behavior of customers.

In addition to benefitting the general customer base, the introduction of EBT card readers may have benefitted SNAP recipients in particular. Although prior studies have found that implementing SNAP/ EBT card readers at farmers markets is associated with increased use of farmers markets by SNAP recipients (Jones \& Bhatia, 2011), increased SNAP redemption rates (Hasin et al., 2016), and market sales (Buttenheim et al., 2012; Hasin et al., 2016), these results add to the growing body of literature assessing the potential dietary impact of these initiatives on SNAP recipients. The one known prior study that evaluated the effect that introducing EBT card readers had on dietary intake found that among 1,320 SNAP recipients surveyed, 99\% reported increased fruit and vegetable consumption attributable to the 
introduction of the EBT card reader (Krokowski, 2016). These results suggest that introducing EBT card readers at farmers markets may be an effective way to increase fruit and vegetable consumption among SNAP recipients.

This evaluation had several limitations that are important to note. This study was primarily conducted as a quality improvement initiative for TLW; as such, our results are not intended to represent the entire TLW customer base and are not intended to be generalized to other initiatives as a way to increase access to healthy foods in other settings. We conducted a one-group, posttest-only study design with a convenience sample of market customers during the spring months of the TLW farmers market. This evaluation did not use a pre-test, but instead relied on retrospective questions asking customers to reflect on how their community food environments and their own dietary intake have changed since beginning to shop at a TLW farmers market. Although similar measures have been used in prior studies (Woodruff et al., 2016), they may have been susceptible to several forms of bias, including social desirability bias, especially given that approximately 19\% of survey respondents reported that they had volunteered for, been employed by, or served on the board of TLW within the previous six months. Although a pre/ post design using valid and reliable measures to assess change in key outcomes of interest would have been a stronger evaluation design, this retrospective measurement approach was most feasible given the limited resources available for this evaluation and the need to keep the survey brief. Additionally, this evaluation did not have a comparison group of shoppers who did not use the TLW farmers markets. The small sample size may have had limited power to detect statistically significant differences between customers based on receipt of SNAP benefits.

\section{Conclusions}

D espite the study's limitations, these results suggest that the TLW urban farmers markets were able to attract low-income customers, that these customers use the market regularly, and that SNAP recipients perceived that they had increased access to and consumption of fresh vegetables as a result of shopping at the market. More rigorous research is needed regarding the most effective methods of increasing access to healthy foods among lowincome Americans and the potential of these initiatives to improve diet and prevent chronic disease.

\section{Acknowledgments}

We acknowledge with gratitude our partners at the G eorgia D epartment of Public Health (D PH), Truly Living Well Center for Natural Urban Agriculture, and all of the participants in this evaluation. We particularly wish to thank April Hermstad, MPH for help with data collection; Sally Honeycutt, MPH for assistance with planning the evaluation; and Regine Haardörfer, PhD , MEd, MS, for assistance with data analysis. We acknowledge with gratitude the support of D PH Commissioner Brenda Fitzgerald, MD; Yvette D aniels, JD; and Jean O 'Connor, JD, MPH, $\mathrm{DrPH}$; as well as former and current Chronic Disease Prevention staff D onna D eCaille, MS, RD , LD, and Andrea Wimbush, MPA, MCHES.

\section{References}

Blanck, H. M., Thompson, O . M., Nebeling, L., \& Yaroch, A. L. (2011). Improving fruit and vegetable consumption: Use of farm-to-consumer venues among US adults. Preventing C hronic D isease, 8(2), A49. Retrieved from https:// www.ncbi.nlm.nih.gov/ pmc/ articles/ PMC3073441/

Bodor, J. N., Hutchinson, P. L., \& Rose, D . (2013). Car ownership and the association between fruit and vegetable availability and diet. Preventive M edicine, 57(6), 903-905. https:/ / doi.org/ 10.1016/ j.ypmed.2013.10.003

Bodor, J. N., Rose, D ., Farley, T. A., Swalm, C., \& Scott, S. K. (2008). Neighbourhood fruit and vegetable availability and consumption: The role of small food stores in an urban environment. Public $\mathrm{H}$ ealth $\mathrm{N}$ utrition, 11(4), 413-420. https:/ / doi.org/ 10.1017/ S1368980007000493

Bunnell, R., O 'N eil, D., Soler, R., Payne, R., Giles, W. H., Collins, J.,... Communities Putting Prevention to Work Program Group. (2012). Fifty communities putting prevention to work: Accelerating chronic disease prevention through policy, systems and environmental change. Journal of C ommunity $\mathrm{H}$ ealth, 37 (5), 1081-1090.

https:/ / doi.org/ 10.1007/ s10900-012-9542-3 
Buttenheim, A. M., Havassy, J., Fang, M., Glyn, J., \& Karpyn, A. E. (2012). Increasing supplemental nutrition assistance program/ electronic benefits transfer sales at farmers' markets with vendor-operated wireless point-of-sale terminals. Journal of the A cademy of $N$ utrition and D ietetics, 112(5), 636-641. https:// doi.org/ 10.1016/ j.jand.2011.12.021

Caspi, C. E., Sorensen, G., Subramanian, S. V., \& Kawachi, I. (2012). The local food environment and diet: A systematic review. H ealth \& Plaœ, 18(5), 1172-1187. https:/ / doi.org/ 10.1016/ j.healthplace.2012.05.006

Certified Naturally Grown. (n.d.). Certified Naturally G rown Produce Standards. Retrieved from https:// www.cngfarming.org/ produce standards

Cohen, D . A., Scribner, R. A., \& Farley, T. A. (2000). A structural model of health behavior: A pragmatic approach to explain and influence health behaviors at the population level. Preventive M edicine, 30(2), 146-154. https:/ / doi.org/ 10.1006/ pmed.1999.0609

D epartment of Health and Human Services. (n.d.). Healthy People 2020 Nutrition and Weight Status, O bjective NWS-4. Retrieved from https:/ / www.healthypeople.gov/ 2020/ topics-objectives/ topic/ nutrition-and-weightstatus/ objectives

Franco, M., Diez-Roux, A. V., Nettleton, J. A., Lazo, M., Brancati, F., Caballero, B.,... Moore, L. V. (2009). Availability of healthy foods and dietary patterns: The Multi-Ethnic Study of Atherosclerosis. A merican Journal of Clinical N utrition, 89(3), 897-904. https:// doi.org/ 10.3945/ ajcn.2008.26434

Franco, M., Diez Roux, A. V., Glass, T. A., Caballero, B., \& Brancati, F. L. (2008). Neighborhood characteristics and availability of healthy foods in Baltimore. A merican Journal of Preventive M edicine, 35(6), 561-567. https:/ / doi.org/ 10.1016/ j.amepre.2008.07.003

Freedman, D . A., Vaudrin, N., Schneider, C., Trapl, E., O hri-Vachaspati, P., Taggart, M.,... Flocke, S. (2016). Systematic review of factors influencing farmers' market use overall and among low-income populations. Journal of the A cademy of N utrition and D ietetics, 116(7), 1136-1155. https:/ / doi.org/ 10.1016/ j.jand.2016.02.010

Hasin, A., \& Smith, S. (2018). Farmers' market manager's level of communication and influence on Electronic Benefits Transfer (EBT) adoption at Midwest farmers' markets. Journal of N utrition E ducation and Behavior, 50(1), 43-50, e41. https:// doi.org/ 10.1016/ j.jneb.2017.09.005

Hasin, A., Smith, S., \& Stieren, P. (2016). Illinois farmers markets using EBT: Impacts on SNAP redemption and market sales. Journal of A griaulture, F ood Systems, and C ommunity D evelopment, 5(1), 179-188.

http:/ / dx.doi.org/ 10.5304/ jafscd.2014.051.015

Jones, P., \& Bhatia, R. (2011). Supporting equitable food systems through food assistance at farmers' markets. A merican Journal of Public H ealth, 101(5), 781-783. https:/ / doi.org/ 10.2105/ AJPH.2010.300021

Krokowski, K. (2016). Evaluating the economic and nutrition benefits and program challenges of EBT programs at farmers' markets. Journal of A griculture, F ood Systems, and C ommunity D evelopment, 4(2), 37-44. http:/ / dx.doi.org/ 10.5304/ jafscd.2014.042.011

Larson, N. I., Story, M. T., \& Nelson, M. C. (2009). Neighborhood environments disparities in access to healthy foods in the US. A merican Journal of Preventive M edicine, 36(1), 74-81. https:/ / doi.org/ 10.1016/ j.amepre.2008.09.025

McCormack, L. A., Laska, M. N., Larson, N. I., \& Story, M. (2010). Review of the nutritional implications of farmers' markets and community gardens: A call for evaluation and research efforts. Journal of the A merican D ietetic A ssociation, 110(3), 399-408. https:/ / doi.org/ 10.1016/ j.jada.2009.11.023

Moore, L. V., \& Diez Roux, A. V. (2006). Associations of neighborhood characteristics with the location and type of food stores. A merican Journal of Public H ealth, 96(2), 325-331. https:/ / doi.org/ 10.2105/ AJPH.2004.058040

Morland, K., Diez Roux, A. V., \& Wing, S. (2006). Supermarkets, other food stores, and obesity: The atherosclerosis risk in communities study. A merican Journal of Preventive M edicine, 30(4), 333-339. https:/ / doi.org/ 10.1016/ j.amepre.2005.11.003

Morland, K., \& Filomena, S. (2007). Disparities in the availability of fruits and vegetables between racially segregated urban neighbourhoods. Public H ealth N utrition, 10(12), 1481-1489. https:/ / doi.org/ 10.1017/ S1368980007000079

Reed, J. A., G rost, L., Mantinan, K., \& Goldenhar, L.. (2013). Final report: Farmers mark ets and community gardens. Michigan D epartment of Community Health. Retrieved from http:/ / www.michigan.gov/ documents/mdch/ FMCG FINAL5142010 329073 7.pdf 
Roubal, A. M., Morales, A., Timberlake, K., \& Martinez-D onate, A. (2016). Examining barriers to implementation of electronic benefit transfer (EBT) in farmers markets: Perspectives from market managers. Journal of A griculture, F ood Systems, and Community D evelopment, 6(3), 141-161. https:/ / doi.org/ 10.5304/ jafscd.2016.063.011

Ruelas, V., Iverson, E., Kiekel, P., \& Peters, A. (2012). The role of farmers' markets in two low income, urban communities. Journal of Community H ealth, 37(3), 554-562. https:/ / doi.org/ 10.1007/ s10900-011-9479-y

Shadish, W. R., Cook, T. D., \& Campbell, D. T. (2002). Q uasi-experimental designs that either lack a control group or lack pretest observations on the outcome. In W. R. Shadish \& T. D. Cook (Eds.), E x perimental and Q uasiE x perimental D esigns for $G$ eneralized Causal Inference (pp. 103-134). Boston: Houghton Mifflin.

Story, M., Kaphingst, K. M., Robinson-O 'Brien, R., \& Glanz, K. (2008). Creating healthy food and eating environments: Policy and environmental approaches. A nnual Review of Public $\mathrm{H}$ ealth, 29, 253-272. https:/ / doi.org/ 10.1146/ annurev.publhealth.29.020907.090926

Truly Living Well Center for Natural Urban Agriculture. (n.d.). T ruly L iving W ell C enter for N atural U rban A griaulture. Retrieved from http:/ / trulylivingwell.com/

United States Census Bureau. (n.d.). A merican FadF inder. Retrieved from http:/ / factfinder.census.gov/ faces/ nav/ jsf/ pages/ index.xhtml

United States D epartment of Agriculture. (2013, last updated April 22, 2016). L ocal F ood D irectories: N ational Farmers M ark et D irectory. Retrieved from https:/ / www.ams.usda.gov/ local-food-directories/ farmersmarkets

Ward, R., Slawson, D., Wu, Q ., \& Jilcott Pitts, S. B. (2015). Associations between farmers market managers' motivations and market-level Supplemental Nutrition Assistance Program Electronic Benefit Transfer (SNAP/ EBT) availability and business vitality. Journal of A griculture, F ood Systems, and Community D evelopment, 6(1), 121-130. http:/ / dx.doi.org/ 10.5304/ jafscd.2015.061.010

Wholesome Wave G eorgia. (n.d.). G eorgia Fresh F or L ess. Retrieved from https:// www.wholesomewavegeorgia.org/ georgia-fresh-for-less/

Woodruff, R. C., Coleman, A. M., Hermstad, A. K., Honeycutt, S., Munoz, J., Loh, L.,... Kegler, M. C. (2016). Increasing community access to fresh fruits and vegetables: A case study of the Farm Fresh Market Pilot Program in Cobb County, G eorgia, 2014. Preventing Chronic D isease, 13, E36. https:/ / doi.org/ 10.5888/ pcd13.150442

Zenk, S. N., Schulz, A. J., Israel, B. A., James, S. A., Bao, S., \& Wilson, M. L. (2005). Neighborhood racial composition, neighborhood poverty, and the spatial accessibility of supermarkets in metropolitan D etroit. A merican Journal of Public $\mathrm{H}$ ealth, 95(4), 660-667. https:/ / doi.org/ 10.2105/ AJPH.2004.042150

Zimmerman, G., Roskos, M. S., Feller, C., \& D urward, C. (2016). D ouble Up Food Bucks Farmers' Market Incentive Program: Food insecurity and fruit and vegetable consumption. The FA SE B Journal, 30(1). https:// www.fasebj.org/ doi/ abs/ 10.1096/ fasebj.30.1 supplement.lb427 